\title{
P.087 RETRACTION - Low back pain relief with a new 32-contact surgical lead and neural targeting algorithm
}

\author{
J. Pilitisis, G. Barolat, J. Rosenow, J. Brennan, A. Bailey, J. Epstein, \\ B. Hammond, C. Metzger, D. Huynh, K. Lechleiter, N. Mekel-Bobrov
}

The Canadian Journal of Neurological Sciences wishes to inform its readers that above referenced abstract from Volume 43, Issue S2 (ABSTRACTS: 51st Annual Congress of the Canadian Neurological Sciences Federation) of the Journal has been retracted. The Journal was informed by the organization that sponsored the study, Boston Scientific, that errors were made during their own (i.e. Boston Scientific) data compilation which skewed the number of subjects and the number of patients with back pain, and therefore significantly altered the results. This decision is also based on the guidelines issues by the Committee on Publication Ethics (COPE). The authors and the sponsoring organization would like to apologize for any inconvenience caused.

\section{REFERENCE}

1. Pilitisis J, Barolat G, Rosenow J, Brennan J, Bailey A, Epstein J, Hammond B, Metzger C, Huynh D, Lechleiter K, Mekel-Bobrov N. (2016). P.087 Low back pain relief with a new 32-contact surgical lead and neural targeting algorithm. Canadian Journal of Neurological Sciences/Journal Canadien Des Sciences Neurologiques, 43(S2), S40-S40. doi: 10.1017/cjn. 2016.189 